\title{
Guidelines for the design and construction of underground portals in open pits - a case study of the Gateway Mine
}

\author{
J.H. Graaf Golder Associates Pty Ltd, Australia \\ T. Parrott Consolidated Minerals, Australia
}

\begin{abstract}
Numerous papers have been written on empirical and deterministic methods of ground support design, yet there is limited published information detailing the application of these methods for underground portals. Newmont Jundee Operation recently started a new underground development called Gateway in the base of an existing pit last mined in the 1990s. Due to the requirements of ventilation and a secondary means of egress, the mine design comprised twin declines from within the existing open pit. To maintain adequate separation between the two portals to avoid ventilation recirculation, the underground design required that one portal be cut in rock of 'good' rock mass quality and the second was to be developed through weak, highly weathered materials.
\end{abstract}

This paper describes the process for determining a suitable portal location in an old open pit with the use of mapping, modelling and diamond drilling. In addition to the data collection process, the ground support design, ground support installation and portal excavation methodology for two different types of ground conditions are discussed.

In addition to the design process, the lessons learnt from the ground support installation and initial excavation processes are documented so that others planning a new mine can utilise these learnings associated with portal design and construction. It is intended that this paper provides a guideline for engineers for ground support design and selection requirements for a portal. Consideration is also given to the installation process and the practical execution of these requirements.

\section{$1 \quad$ Introduction}

Newmont Jundee Operation (NJO) is located $50 \mathrm{~km}$ north-east of Wiluna in Western Australia and within the Eastern Goldfields Province of the Yilgarn Craton (Cassidy et al., 2006). The deposit occurs within a north-northwest trending corridor of lower greenschist facies Archaean rocks to the east of the sub-vertical and west-dipping Nimary Fault. Mineralisation is structurally controlled in quartz-calcite-pyrite veinlets. The weathering profile ranges from 60 to over $150 \mathrm{~m}$ depths in this area.

Open pit mining started in mid 1995 and over 20 pits were mined until open pit mining ceased in 2008. There are three separate operational underground mines: Barton, Invicta and Gateway (Figure 1). Underground development of the Barton mine commenced in August 1997, Invicta in 2004 and most recently the Gateway underground mine development started in early 2011.

Plans to develop Gateway focused on re-entering the previously mined Nim4 pit and locating the portal below the deep weathering profile. This plan was designed to keep the ground support costs as low as possible but also to allow for faster development rates in more favourable rock mass conditions. The twin decline layout included a primary access and the second portal being the return airway and second means of egress from the mine. The initial design had one portal and included a surface return ventilation shaft in a nearby adjacent and shallow pit. However, due to time constraints and high costs of conventional shaft sinking through at least $100 \mathrm{~m}$ of weathered material, the addition of a second portal ended up being more cost effective. 


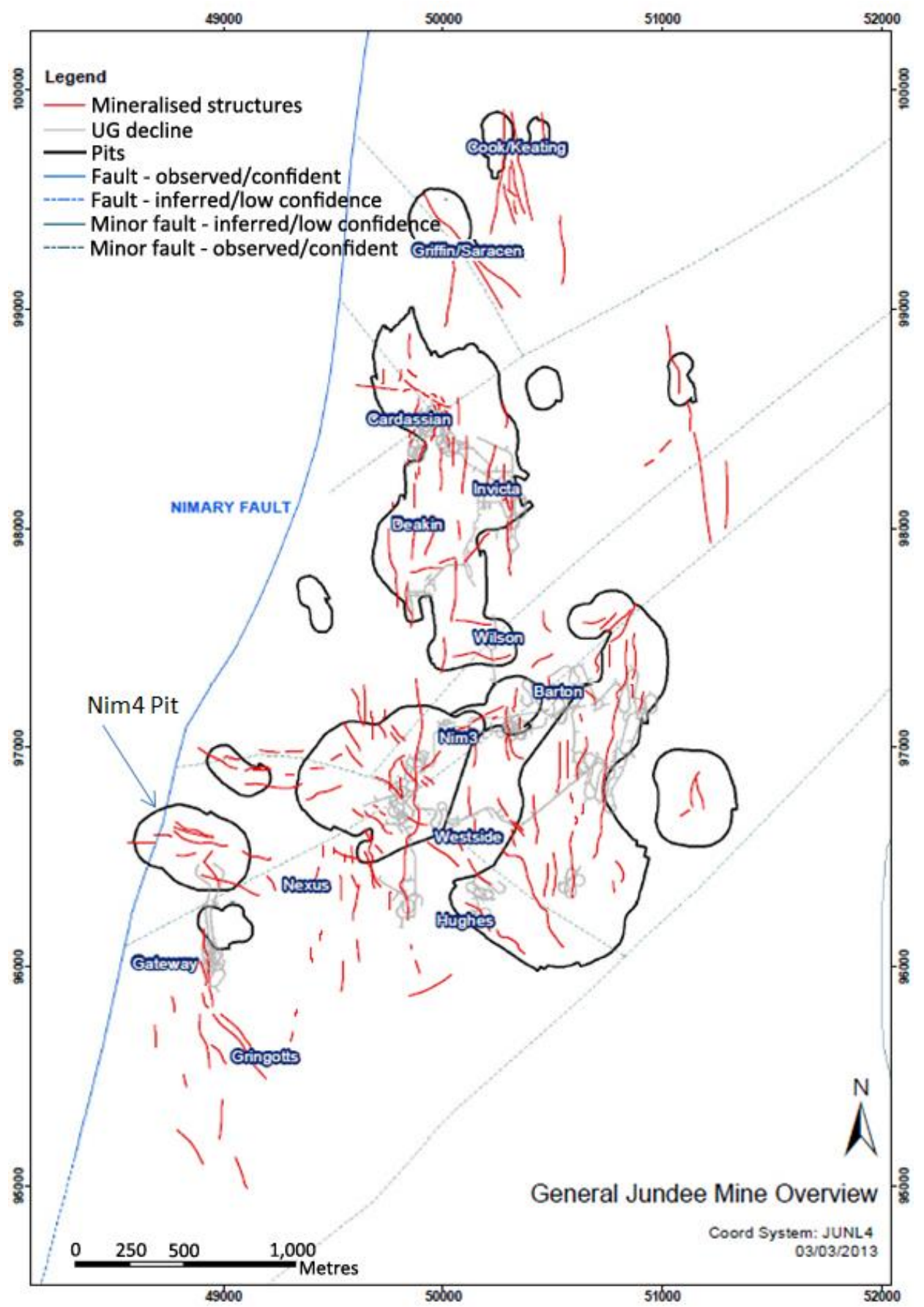

Figure 1 General overview of Jundee showing some of the open pits and the underground mine locations

Limited space was available in Nim4 to maintain adequate separation between the two portals to avoid air recirculating. Additional limitations included the pit geometry, ability for both heavy and light vehicles to enter and exit the portal safely, and the need to keep the openings above the 1:100 year flood line due to the presence of a pit lake. Both declines were $6 \mathrm{~m}$ high by $5.8 \mathrm{~m}$ wide with the main decline in the eastern wall of the pit, and the ventilation portal into the southern wall of the pit (see Figure 2 for portal locations). 


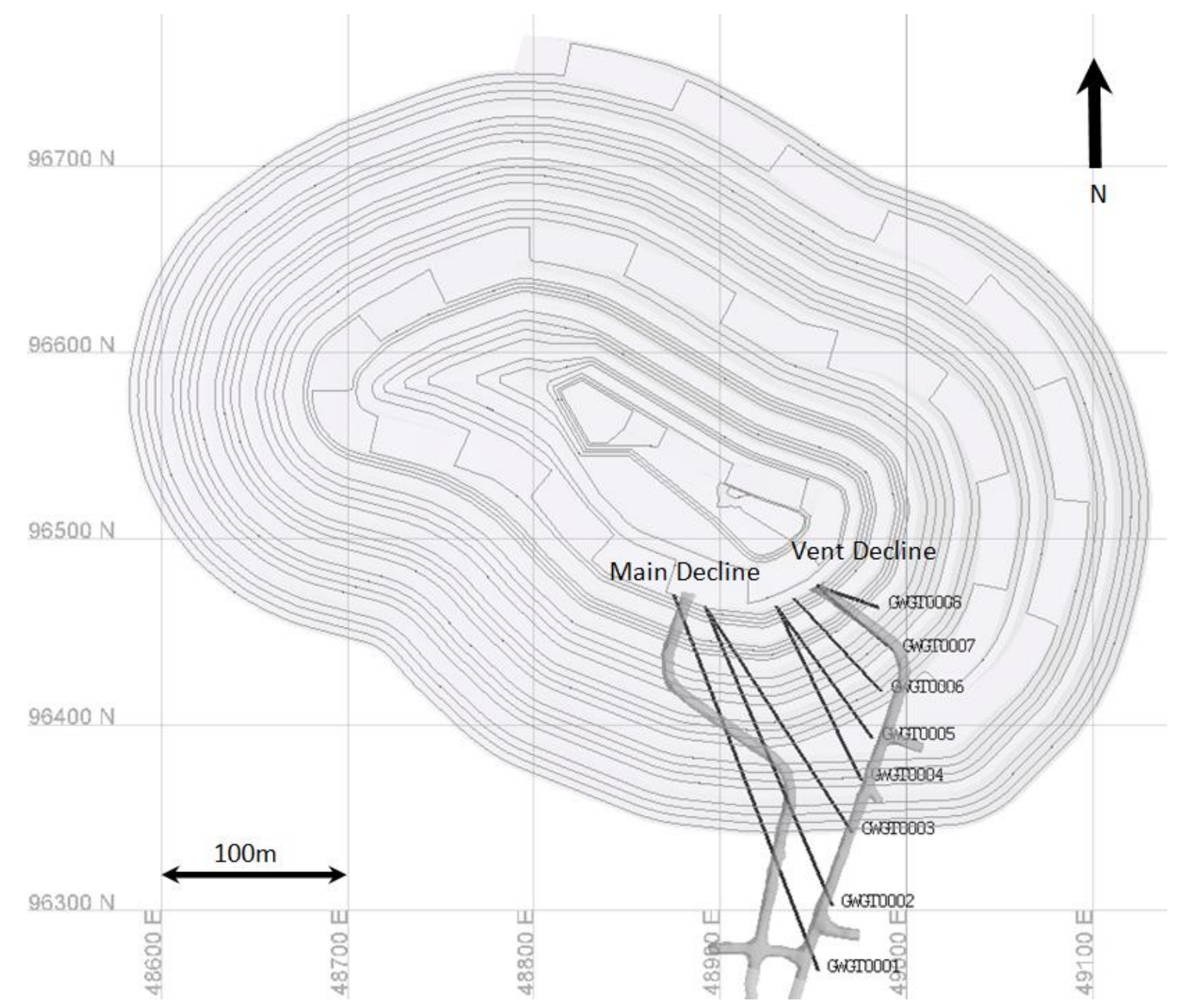

Figure 2 Plan view of the Nim 4 Pit and the Gateway Declines

Slope instabilities at portals are not uncommon as they often present challenges in terms of stability and can be difficult in terms of managing ground control (Rogers and Haycocks, 1988, 1989). Difficulties in managing ground conditions arise as a high proportion of portals are excavated in weathered, highly discontinuous and stress-relieved near-surface rock masses (Rogers and Haycocks, 1988, 1989). Additional factors controlling portal stability include rock type, geological structure and blasting damage from open pit mining and tunnel development. Whilst it is not a highly stressed mining environment, the abutment stresses are concentrated at the base of the pit and therefore timely support and reinforcement is required to the level needed for permanent infrastructure.

At Jundee, portal instabilities were experienced during the development of the first underground portal for the Barton Decline during the very first cut. Due to improved rockmass understanding a detailed geotechnical investigation was implemented to reduce the likelihood of instabilities occurring for the portal location and ground support design requirements of the Gateway Mine. Two engineering approaches were required for portal design and construction; slope stability assessment and tunnel engineering. The consequence of portal failure was deemed high due to the mine design comprising twin declines from within the same pit.

These portals are in a unique structural setting, whose primary purpose is to provide safe access for men, material and equipment to the underground over a definable project life. Two areas of concern were considered when approaching the design and ground support of the underground portals:

1. The stability of the pit slope and face that the portal is being cut into. 
2. The stability of initial underground development due to blast damage and stress relief in this area. The likelihood of instability is historically higher in the first 20 to $30 \mathrm{~m}$ of decline development (approximately 5 drive diameters away from the pit surface).

\section{Overview of existing methodologies}

Rogers and Haycocks (1988) recommend that the analysis sequence for an underground portal in a rock slope should be a combination of empirical and analytical methods as follows:

- Geological characterisation of the site.

- Overall slope stability.

- Slope stability in the immediate portal area.

- Underground excavation stability.

Joint orientation adjustments for high angle portal slopes were recommended for use with the Bieniawski's RMR rock mass classification system (Rogers and Haycocks, 1989).

The Rock Tunnelling Quality Index, Q (Barton et al., 1974) contains an internal adjustment factor for the Jn value when looking at portals, i.e. artificial increase. Hutchinson and Diedrichs (1996) state in their chapter on application of engineering principles for the Rock Tunnelling Quality Index, $Q$, that "for critical intersections and access portals use 2.0 to $3.0 \times J n$ to evaluate $Q^{\prime \prime}$. Presumably this additional factor is designed to account for added complexity in the dimension of the excavation, additional degrees of freedom and an allowance for the excavation method. However, we have not been able to find any justification of this added note in the rock mass classification system in the original paper or in subsequent references.

\section{Data collection process}

The following points summarise the data that was collected and analysed to determine the ground support requirements for the portals and the initial underground development.

\subsection{Historical data}

The initial phase of any new project must include a review of existing information. In this instance all available information from mining of the open pit was compiled and reviewed where possible. This included but was not limited to:

- Old open pit ground control management plans (GCMP).

- Old geotechnical and open pit studies and reviews.

- Geology maps including grade control and pit wall mapping.

- Production and other drilling records.

- Dewatering data.

- Discussions with previous operational personnel.

- Historical hydrogeological reports.

Unfortunately, either poor record keeping or archiving of hard copy data meant that there was little historical information available for the existing open pit. However, there were a number of historical geotechnical consultant reports available for both the initial stages of the two nearby underground mines. Additionally, a geotechnical consultant report detailing the Barton portal instability issues was located which proved useful. 


\subsection{Open pit stability assessment/review}

A specialist open pit geotechnical engineer from Newmont reviewed the stability of the open pit prior to earth works recommencing. This review included:

- Assessment of the road conditions.

- Assessment of the bund stability.

- Perimeter walk around and walk around of accessible benches.

- Recommendations for remediation.

- Recommendations for reinstatement of monitoring.

- Assessment of the long term stability of the pit for re-entry.

\subsection{Mapping}

Initial desktop studies and discussions with the mine planning engineers determined the locations which would be most suitable for portal construction and easiest from a mine design perspective. The next step was to validate these areas through pit mapping and more detailed structural mapping. Old geology maps of the pit provided an indication of the host lithologies and areas of more complex structure.

Upon inspection of the pit it was clear that finding two locations at suitable distances from each other would be more difficult than originally anticipated. This was due to a number of factors including:

- Bench width and ramp loss due to minor instability over the years. This applied to the benches above the portal and also to the level that the portal was to be constructed in.

- Insufficient bench heights (a minimum cover from portal back to overlying bench of at least twice the portal width was required, particularly in the highly weathered material).

- Natural artesian springs were flowing on the west side of the pit, along a major fault.

- There was insufficient fresh rock exposure for both portals due to the restrictions of flood levels imposed from the pit sump.

One portal would be constructed within slightly weathered to fresh rock, and it was a matter of finding a more favourable position for the second portal within the highly weathered material. Once two suitable locations were found and validated with the planning engineers then a program of detailed mapping was undertaken at the two portal locations. The mapping data was collected manually and subsequently assessed.

The purpose of the scanline mapping was to measure the orientations of structures present around each of the portal locations with a focus on identifying any major structural features. Structural orientations were then assessed using dips.

\subsection{Diamond drilling information}

Whilst there was substantial geotechnical information collected during resource definition and exploration drilling, this information was located nearly $300 \mathrm{~m}$ from the portal entrances. To define the ground conditions in the vicinity of the two portals, an underground diamond drilling rig already active on site was used to drill eight diamond drill holes along the first $200 \mathrm{~m}$ of decline development. The locations of these drill holes are shown previously in Figure 2.

The underground diamond drilling contractor was chosen as these were the only drill rigs on site capable of drilling geotechnical holes with a maximum dip of $-10^{\circ}$. Fanning the holes out from within the pit and along the alignment of the decline provided maximum coverage of expected ground conditions in comparison to drilling from ground surface. 
The open pit had already been assessed for stability, however, drilling into the face of an existing batter was a new experience for the underground diamond drillers. To provide a safe working environment for the drillers, the drill rig was set up within a modified sea-container. Old drill rods were placed on top of the sea container and underground weld mesh was placed over the top for rockfall protection. Drilling was restricted to dayshift only due to lighting issues. An example of the drilling set-up in the pit is shown in Figure 3.

Geotechnical logging included detailed geotechnical logging independent of rock mass classification regime as well as detailed structural logging.

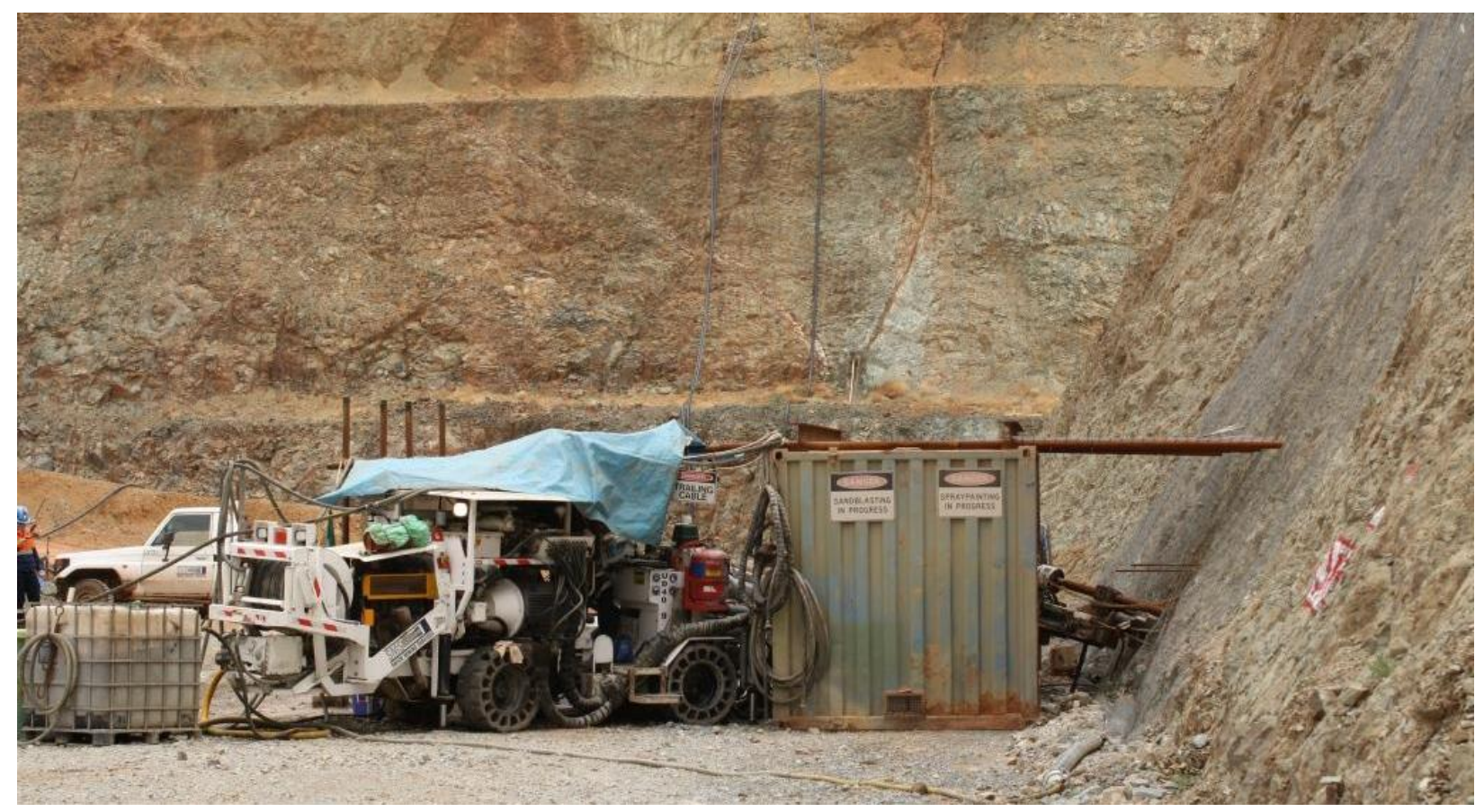

Figure 3 Set-up of an underground diamond drill rig within an old open pit

\section{$4 \quad$ Rockmass characteristics}

\subsection{Ventilation portal}

The ventilation portal was located in the deepest part of the pit and would be cut into slightly weathered to fresh basalt of moderate to high strength (Figure 4). There were few structures and no significant faults or large-scale structures in the vicinity and the bench height was at least $20 \mathrm{~m}$ allowing for sufficient crown pillar above the portal. Any instability in this portal was expected to result from blocky wedge or planar type failure.

The four boreholes targeting this location indicated a good to very good quality rock mass with a Q-rating of 40 or more. These holes indicated that previous blast damage extended up to $1.0 \mathrm{~m}$ behind the wall. Three geotechnical diamond drill holes were unable to be grouted due to water flowing from the holes. The rates of these flows were minor, however, this was an indication of the possibility of intersecting waterbearing structures during decline construction. 


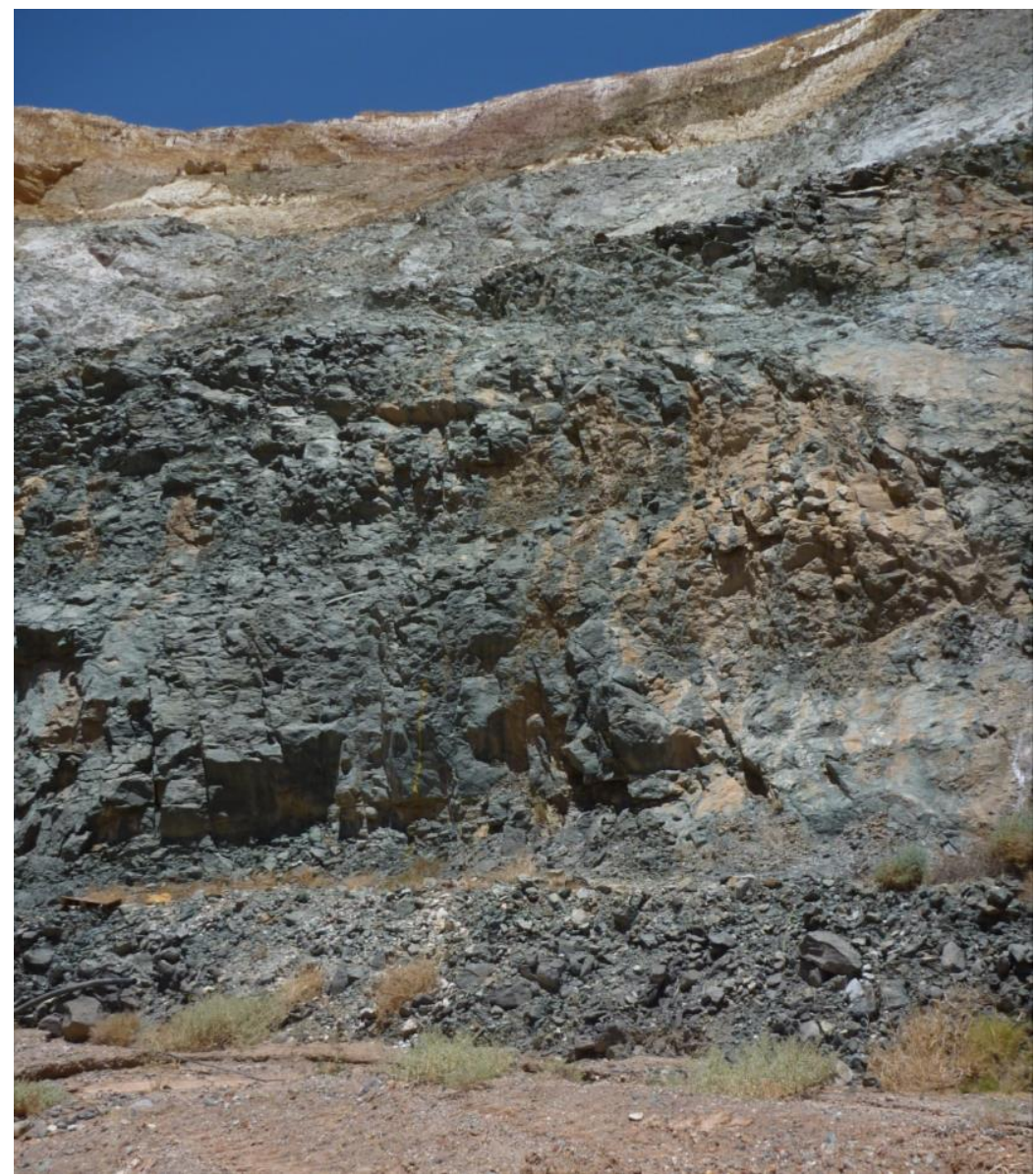

Figure 4 View of the ventilation portal site on the east wall of $\mathrm{Nim}_{4} \mathrm{Pit}$

A kinematic assessment of major defect sets was undertaken in dips. No pure planar failures were possible at the bench scale and no structures were present that were favourable for toppling failure, however, wedge failure was considered a possibility. Average joint set orientations were used in a Swedge analysis to evaluate the safety factor and probability of failure for wedge failure surfaces in the pit wall.

Current industry practice is to design benches in open pits to have certain reliability, with some minor instability being acceptable. Mine entry portals are a critical link to the underground mine, they are high traffic areas or areas where very expensive infrastructure is to be placed. As a result these areas should have a high safety factor against instability where even minor instability is not tolerated.

\subsection{Main decline portal}

Analysis from drill core and mapping observations showed this portal will be constructed in highly weathered felsic porphyry and basalt clays for approximately the first $30 \mathrm{~m}$ of development after which it would be fresh, hard basalt (Figure 5). Significant core loss was observed in the initial $25 \mathrm{~m}$ of coring due to poor ground conditions and $9.3 \mathrm{~m}$ of core loss in the first $16 \mathrm{~m}$ of one hole was observed (Figure 6). Given the weak nature of this material, any failure of the bench in which this portal was expected to be developed was likely to be circular in nature. Slide ${ }^{\mathrm{TM}}$ was used to evaluate the safety factor and probability of failure for circular failure surfaces in the pit wall. 


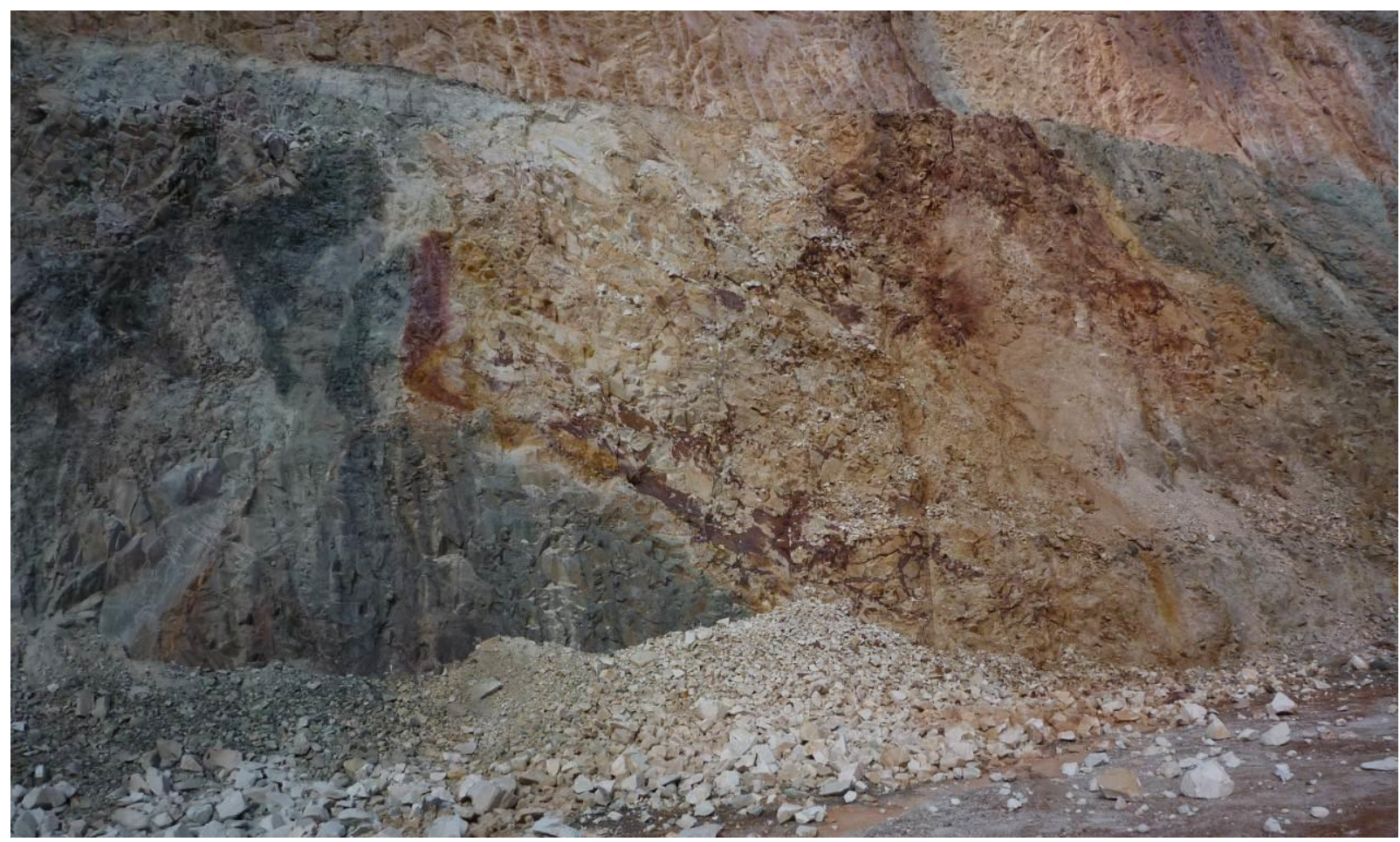

Figure 5 View of the southern wall of the pit looking at the location for the main decline portal

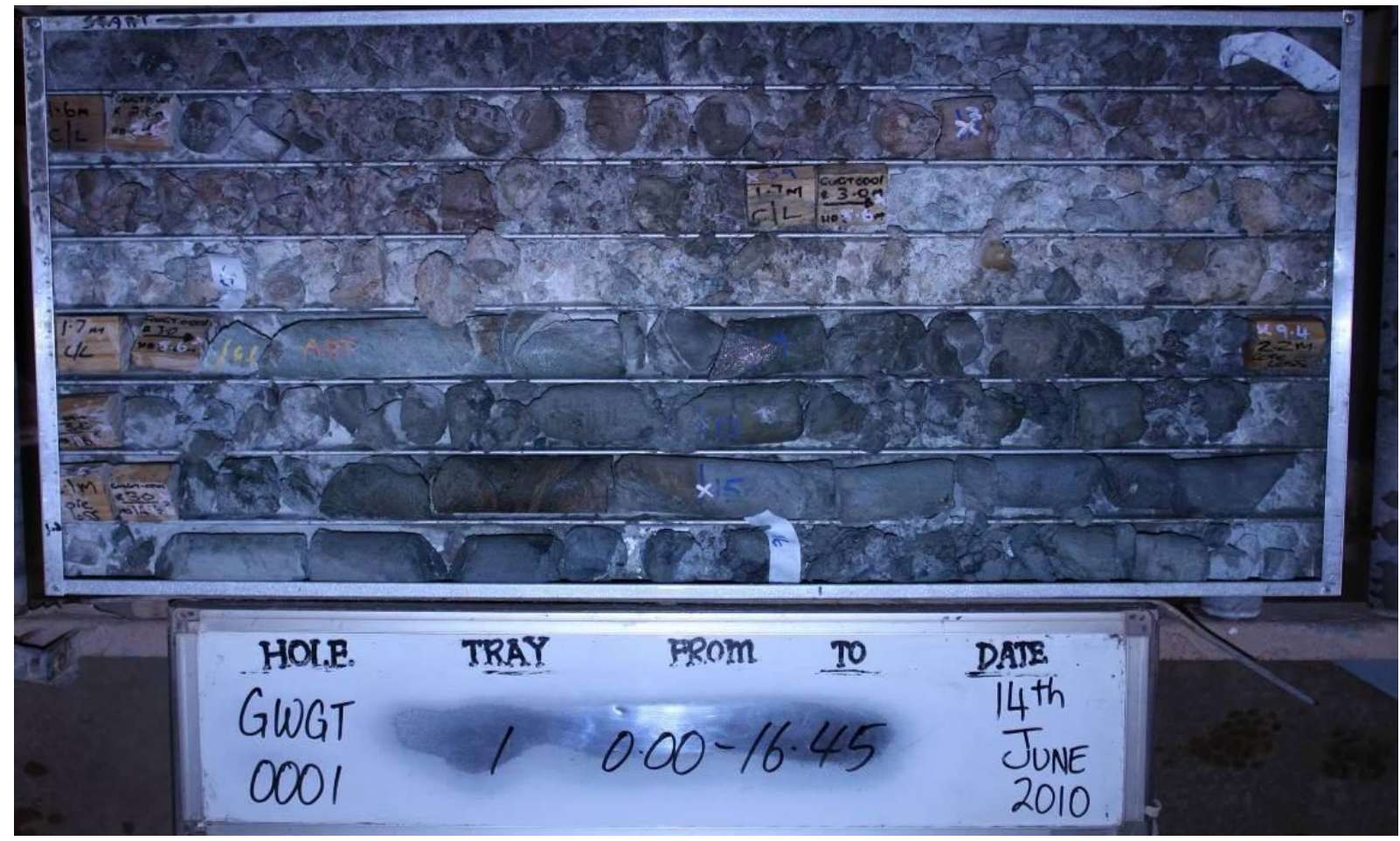

Figure 6 Tray 1 from GWGToo1 showing extremely poor ground conditions encountered in the drill hole and significant core loss

As no rock property test work could be undertaken for this core, the shear strength values used for the initial pit design located in the historical Open Pit GCMP were used for the analysis. In the interests of conservatism, the lowest values for highly weathered basalt and porphyry from the historical data were used initially and then the rock mass strength assessed as a sensitivity analysis. 
Slide analyses estimated that the FoS of the worst possible bench-scale instability that could occur in the pit wall had a depth of failure of $6.4 \mathrm{~m}$ and a FoS of 0.75 . Prudent mine design for permanent infrastructure require a minimum FoS of 2.0, therefore significant ground support and reinforcement requirements were required for this portal to prevent a potential instability from occurring. As with the ventilation portal, one of the geotechnical cover drill holes had water flowing from it.

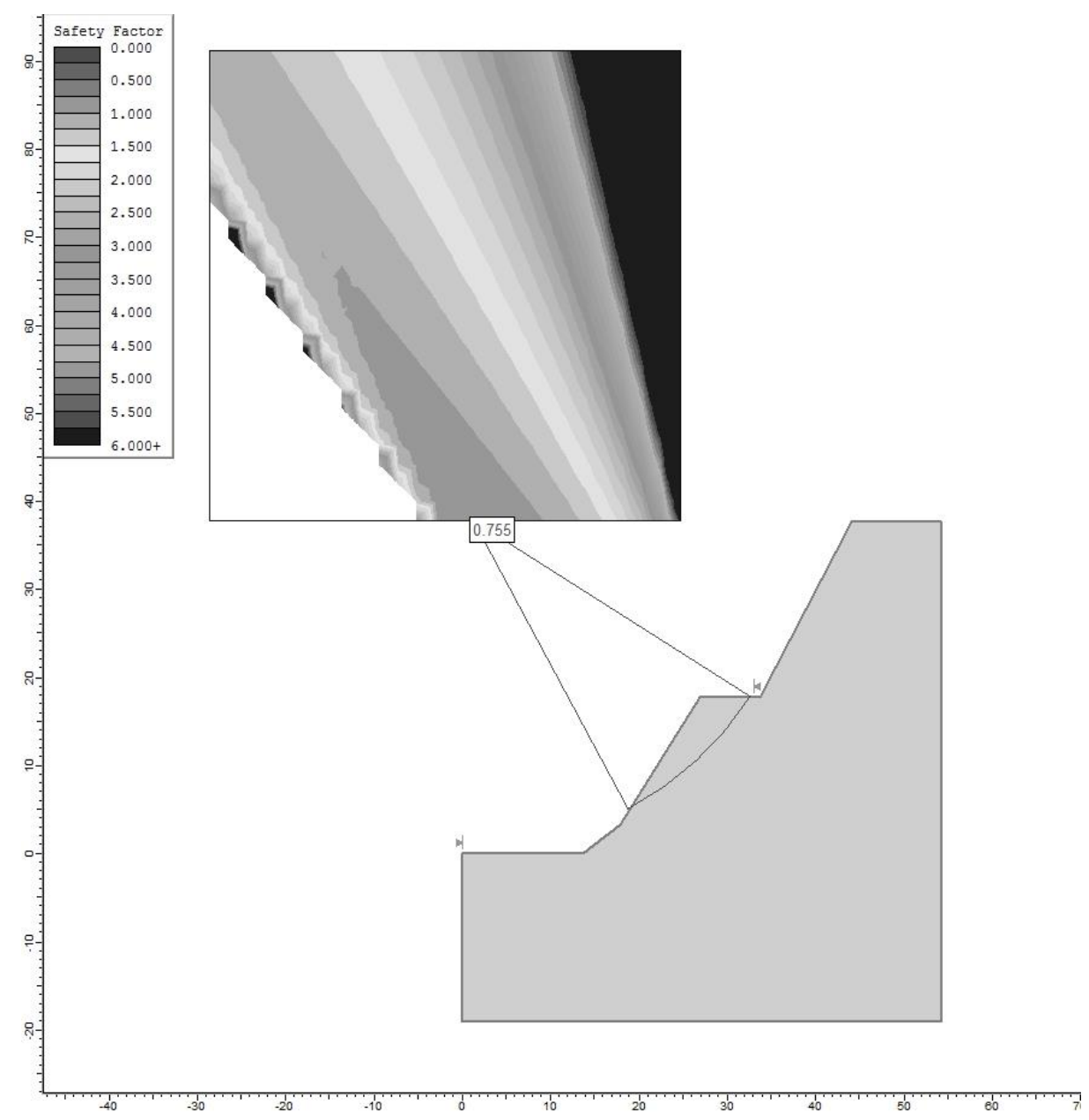

Figure 7 Slide analysis showing the FoS for the worst possible failure condition in the batter of the main decline portal

\section{$5 \quad$ Ground support design}

Following data collection, analysis and interpretation the initial phase of the ground support design focused on stabilising the batter face. A design FoS of 2 was chosen due to this being permanent infrastructure of high importance and also a high traffic area. The second phase of ground support design was for the initial decline development. A key aspect of the ground support design was to choose support elements that were readily available and that were easy to install.

\subsection{Ventilation portal}

The results from the kinematic analysis showed that all potential wedge failures could be adequately supported with a $2.0 \times 2.0 \mathrm{~m}$ staggered pattern of $2.4 \mathrm{~m}(20 \mathrm{~mm})$ grouted threadbar. In addition to this, a number of pre-tensioned, twin strand $500 \mathrm{kN}$ bulbed and inclined cable bolts were planned immediately above the portal excavation in order to provide deeper stabilisation and active surface pressure to the face (Figure 8). 
As only minimal ground support was required to stabilise the potential wedges, the majority of the ground support required for this portal consisted of surface support and rockfall protection to prevent any minor rockfalls from hitting people, equipment or infrastructure.

Galvanised chain link mesh was utilised for the face and $50 \mathrm{~mm}$ fibre reinforced shotcrete for approximately one diameter, i.e. $6 \mathrm{~m}$, of the decline around the portal excavation for increased surface support durability and to reduce the likelihood of overbreak during initial excavation.

A summary of the ground support and rock reinforcement requirements for this portal are listed below:

- $8.0 \mathrm{~m}$ long bulbed twin strand cable bolts installed sub-horizontally ( $5^{\circ}$ incline) on a staggered $2.0 \times 2.0 \mathrm{~m}$ pattern immediately around the portal perimeter, pretensioned to $5 \mathrm{t}$ per strand.

- $2.4 \mathrm{~m}$ long $20 \mathrm{~mm}$ grouted and plated threadbar installed on a staggered $2.0 \times 2.0 \mathrm{~m}$ pattern.

- Chainlink mesh G80/2 draped over the face, spaced off the rock face to insure embedment in the middle of fibrecrete.

- $50 \mathrm{~mm}$ of $32 \mathrm{MPa}$ fibrecrete (40 kg/m $\mathrm{m}^{3}$ steel fibres) sprayed to approximately one diameter of the excavation around the perimeter of the portal.

- All ground support and reinforcement elements are galvanised.

\subsubsection{Equipment and methodology}

Once the ground support regime had been decided the next phase was installation. A ground support contractor was awarded the contract for ground support installation. A Hi-Reach drill was sourced for the project to drill the larger cable bolt holes. A Cherry Picker, Marini Drill and air leg were used to drill out remaining rockbolt holes and for the installation and grouting of bolts.

Where the bench face was over $20 \mathrm{~m}$ high, a Marini Drill was lowered over the edge of the berm and used to drill the rockbolt holes.

\subsubsection{Development of the ventilation portal}

To increase the stability of the excavation, the initial portal blast was designed to be smaller in dimension than the final design size, i.e. $4 \mathrm{~m}$ wide $\times 3 \mathrm{~m}$ high. The remaining rock was then to be stripped into the smaller drive using carefully controlled perimeter blasting with the aim of reducing blast damage to the final portal walls.

Short length development rounds of $2 \mathrm{~m}$ length were implemented for the first $10 \mathrm{~m}$ of development. This had several benefits including keeping the ground support close to the face and therefore reducing the effective unsupported span at any given time, and reduction of instantaneous charge weight per delay and therefore reducing blast damage to the rock mass.

Ground support consisting of galvanised wire mesh and Stiff Split Sets were installed to the face after each cut. In-cycle cabling of the portal and decline backs was required for $12 \mathrm{~m}$ into the decline and in-cycle fibrecrete to a thickness of $50 \mathrm{~mm}$ was sprayed in this section from gradeline to gradeline. Cable ring spacing was $2.0 \mathrm{~m}$ with three $6 \mathrm{~m}$ long twin strand bulbed cable bolts per ring spaced $2.0 \mathrm{~m}$ apart. Five rings were designed (Figure 9) for the initial development. Three of these cable bolt rings were installed through the bench above prior to development using the Marini drill for pre-reinforcement of the decline. This meant that as they were intersected during development, the strands were cut to size, plated and posttensioned as development proceeded, speeding up the development cycle. 


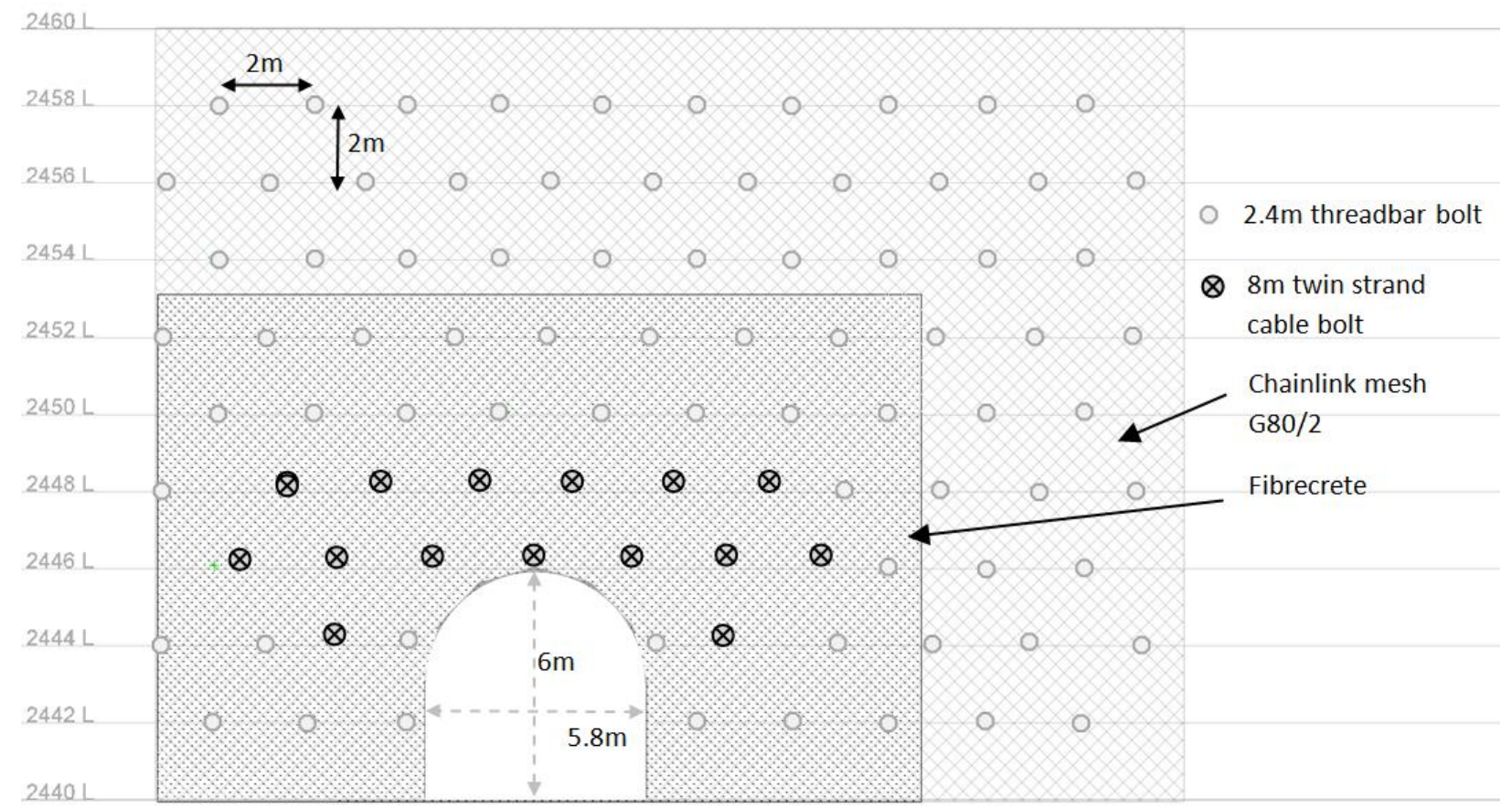

Figure 8 Perspective view of the ventilation portal showing the ground support design

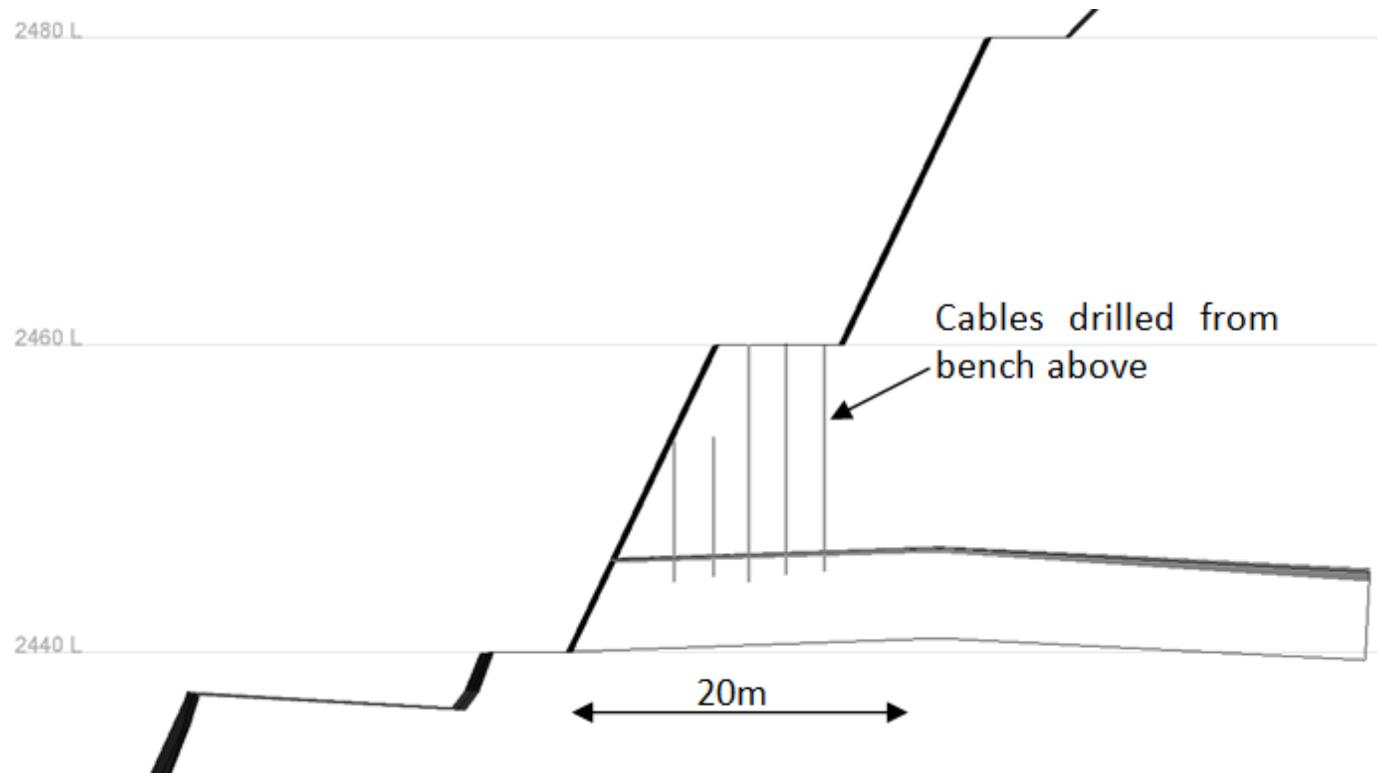

Figure 9 Section view of the decline showing the cables drilled from the bench above

\subsection{Main decline portal}

Limit equilibrium analysis using Slide indicated that the total driving force of a potential circular failure was $520 \mathrm{KN}$ per metre slice. To achieve a FoS of 2 for the slope, then a driving force of 1,040 KN was required to be supported to make the portal location stable for the long term.

Sufficient restraining force was achieved in the modelling through installing a series of $4 \times 250 \mathrm{kN}$ bulbed

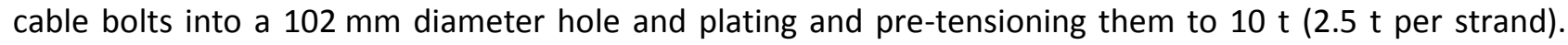
Twenty of these cable bolt holes were required to sufficiently support the maximum possible failure. The cable bolt configuration required a minimum length of $9 \mathrm{~m}$ in length to provide sufficient embedment beyond the potential depth of failure. 
Spiling (forepoling) bars ( $32 \mathrm{~mm}$ threadbar) were designed and installed around the perimeter of the arch of the decline profile to provide secondary support. These were on a $0.5 \mathrm{~m}$ spacing covering the full arch section of the excavation design and were $12 \mathrm{~m}$ long. The spiling bars were installed to pre-reinforce the ground prior to development by providing an umbrella of reinforcement. This resulted in improved productivity in the expected difficult development conditions and reduced the risk of backs unravelling (see Figure 10 for general ground support configuration).

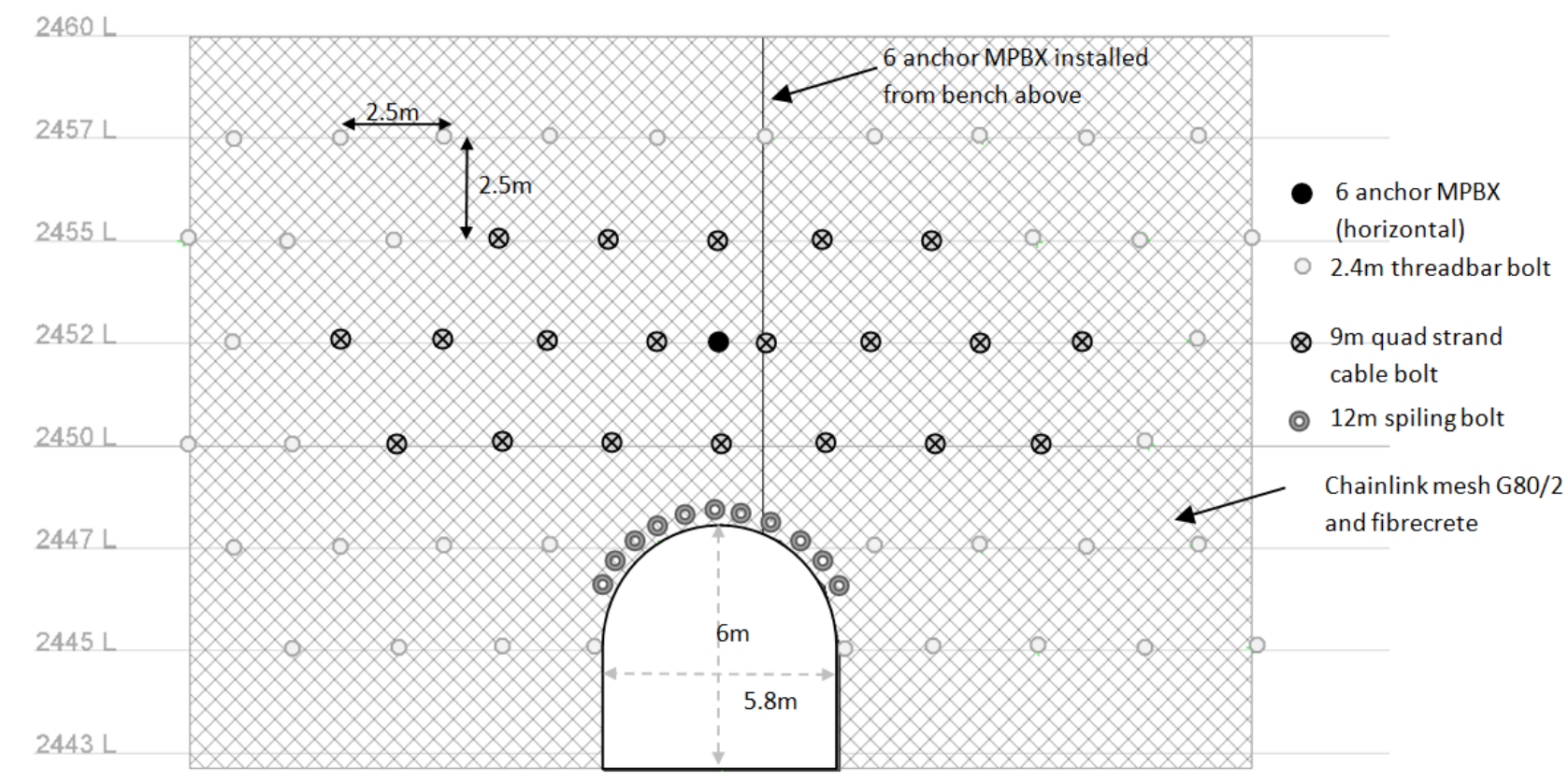

Figure 10 Ground support for main decline

The total ground support and reinforcement required for this portal is summarised below:

- $9 \mathrm{~m}$ quad-strand bulbed cable bolts installed into a $102 \mathrm{~mm}$ diameter hole, plated and pretensioned to $10 \mathrm{t}$ with $4 \mathrm{~m}$ of embedment, installed sub-horizontally on a $2.5 \times 2.5 \mathrm{~m}$ staggered pattern.

- $2.4 \mathrm{~m}$ long $(20 \mathrm{~mm})$ grouted threadbar installed on a $2.5 \times 2.5 \mathrm{~m}$ staggered pattern.

- $11.8 \mathrm{~m}$ long $(32 \mathrm{~mm}$ ) grouted horizontal spiling bars installed $0.5 \mathrm{~m}$ from the perimeter of the portal at a spacing of $0.5 \mathrm{~m}$.

- Chainlink mesh G80/2 draped over the face and pinned in the middle of fibrecrete.

- $100 \mathrm{~mm}$ of $32 \mathrm{MPa}$ fibrecrete (40 kg/m $\mathrm{m}^{3}$ steel fibres).

- $3 \times 6$ anchor point MPBX (Multi Point Borehole Extensometer), one installed into the face and two from the bench above to monitor and slope/bench deformation during development of the decline and also for long term monitoring.

- Timber-lagged steel set arches on a nominal $1.2 \mathrm{~m}$ centre spacing for the first $20 \mathrm{~m}$ of development in the weak highly weathered material.

\subsubsection{Ground support design and selection for decline}

The main decline presented an issue in terms of designing and selecting an adequate ground support and reinforcement regime. Complicating factors included:

- Pit wall consisted of highly weathered to soil like material, therefore typical ground support design approaches were not applicable as rock mass characterisation does not apply to materials of this nature. 
- The pit surface provides additional degrees of movement and lack of confinement to restraining potential blocks or rock mass displacement.

It has been observed first hand by the authors and through conversation with industry peers that portals located in highly weathered materials from within an historical pit more often than not use steel arches with timber lagging. The arches are used as a means of providing long-term passive support to the initial entrance to the mine workings. It was therefore seen as a requirement for the project.

The problem of selecting an appropriate steel arch configuration presented itself. This would be driven by the demand requirements of the rock mass. It soon became apparent that:

- Suppliers are, in general, completely unaware of the load-bearing capacities of steel arches they are marketing for sale.

- Not many supply companies have a range/catalogue of arches available for review.

- Steel arches within the Australian mining industry are typically for one-off specialty projects.

- Little thought is typically put into the loading regime in situations requiring steel arch support, and hence little thought is put into the design of the steel arch.

- It appears that steel arch sizes are typically determined by undocumented experience/case histories, i.e. someone saw arches of a particular size work at one mine, therefore it should work for us, or rule of thumbs.

- The criteria for specifying the use of steel arch support is unclear, but is loosely applied to anything that is being developed in weathered/weak material.

Four methods were used to determine an appropriate design load for the initial section of decline. They were Terzaghi's Rock Load Theory (Terzaghi, 1946), Singh's modification of Terzaghi's theory (Singh et al., 1995), Barton's Support Pressure and a Dead Weight calculation (Barton et al., 1974). The design load was then provided to a structural engineer for analysis of the steel set arches.

The arch configuration required a full radius for the arch section, constructed from a single universal column (UC, and no joints within the arch section). Members were analysed in the design software package Microstran, which is a frame analysis program used for design and analysis of steel structures. The steel arch design ignored the support benefits of the 'temporary' ground support layer for added conservatism.

A 'temporary' ground support regime was designed for installation following excavation but prior to setting of the arches. This consisted of in-cycle fibrecrete, stiff split set bolts, and mesh, followed by another application of shotcrete and in-cycle cable bolting. Development rounds were limited to $1.5 \mathrm{~m}$ in length for the initial stages of the portal excavation.

\subsubsection{Installation / implementation of ground support}

As with the ventilation portal, the High Reach drill was used to drill the larger cable bolt holes above the portal, the spiling bar holes and was able to reach the uppermost rockbolt holes. The teleporter was used to install the rock and cable bolt support elements. Additionally, a pad was built to enable a higher reach of drilling equipment when the high-reach drill rig was no longer available.

Development was initially restricted to dayshift only, to allow for greater supervision and limit the activities to one crew only. Steel arches were manufactured in such a way to allow for pre-assembly outside the portal on steel skids, five arches at a time. The arches were then advanced (pushed in) with each development round and acted as a canopy in addition to the temporary support regime (Figure 11). The arch design allowed flexibility so that if ground conditions deteriorated at the face, the arches could be set in place and switched over to standing arches in cycle. This, however, never eventuated. Once the portal reached better ground and arches were no longer required, the steel arches were lagged with inflatable grout packs or timber (timber was used when the distance between the arch and the excavation surface 
was too great for the grout packs). The lower $1.5 \mathrm{~m}$ of the arch sides were concreted into place to provide protection against equipment damage and increase rigidity.

\subsubsection{Development of the decline portal}

Given the weak nature of the rock mass at this location it was decided that the portal should not be developed in full rounds using conventional drill and blast techniques. Initially the face was squared up with a backhoe then a remotely controlled machine (Brokk 440, usually used for demolition works) was used to advance the face through scaling. This gave greater control over the excavation profile and advance rate, and removed the need for explosives. The backhoe use was continued for removal of the spoil only.

Each advance was limited to $1.5 \mathrm{~m}$ at a time and ground support was installed to the face after each small 'cut' or advance. Steel set arches were installed progressively with development.

Ground support and reinforcement for development within the portal consisted of stiff split set bolts with $2.4 \mathrm{~m}$ bolts in walls and $3.0 \mathrm{~m}$ long in backs and shoulders. Stiff Split sets were used as they provide greater longevity of support than regular friction bolts. In-cycle fibrecrete to $75 \mathrm{~mm}$ thickness was applied directly to the excavation surface, followed by stiff split set bolts and mesh, then another $25 \mathrm{~mm}$ layer of plain shotcrete over the top of the mesh. Twin strand $6 \mathrm{~m}$ cable bolts were installed in-cycle on a $2 \mathrm{~m}$ ring spacing. Spiling bars continued to be installed around the perimeter of the arched profile at $0.5 \mathrm{~m}$ centres for the first $30 \mathrm{~m}$ of development and were overlapped to ensure continuity of support.

Once the development was through the highly weathered clays and highly fractured rock and ground conditions improved, then surface support was reduced back down to mesh and stiff split set bolts only.

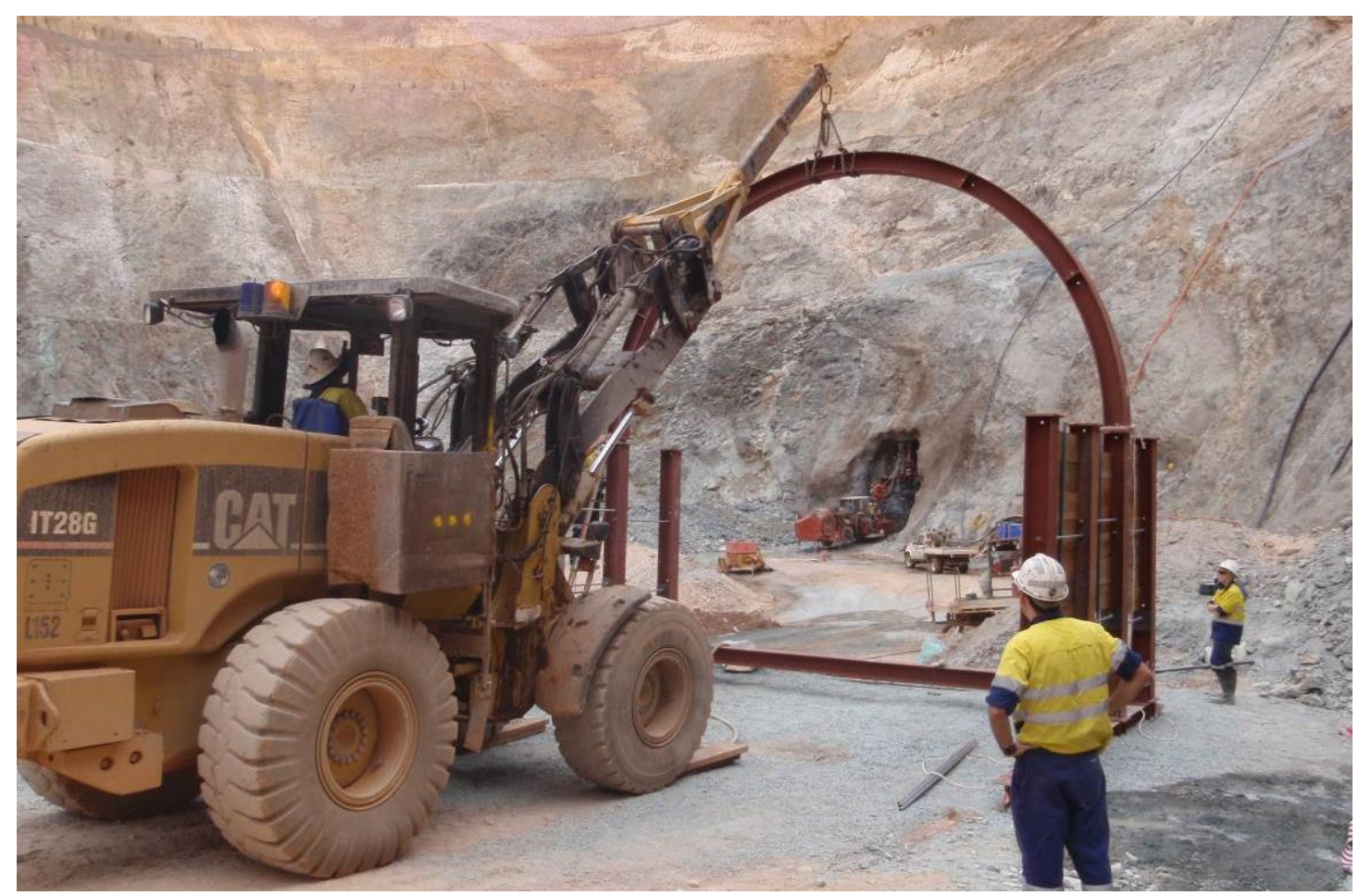

Figure 11 Pre-assembly of the steel arch sets outside the portal

\section{$6 \quad$ Monitoring}

In order to monitor rock mass displacement in response to excavation, the effectiveness of the support and the effect of development on the stability of the slope of the main portal, three multi point borehole extensometers (MPBX) were installed into the wall around the main decline portal. These were deemed necessary due to some uncertainty in the design methodology and a desire to improve the overall understanding of the mechanics of portal development. 
Monitoring of the MPBX's indicated that minimal to no movement was occurring. This was corroborated with observations in the development in that there was no observable damage or cracking within the fibrecrete liner. If displacements were occurring at magnitudes great enough to cause concern for development, then there would have been obvious visual signs.

\section{$7 \quad$ Learnings}

The best planning could not stop unforeseen events from taking place. When it came time to cutting the first cut of the ventilation portal, the mark up of the face incurred some error resulting in damage of ground support elements and hence rehabilitation. The portal firing requirements were not effectively communicated across swings.

Practicality of ground support installation was a key feature in this study, of which manual handling and equipment limitations are fundamental. For example, how high can your drill reach? How long are the holes it can drill? What is the minimum angle that they can drill?

Cosmetic factors can also influence design. For example the areas between the portals were also meshed with draped mesh for rockfall protection because of concerns by the underground personnel even though this had been scaled.

A lack of available operators with experience in portal construction was an issue initially. With the turnover in the industry in the last decade there is a lack of operators with this experience. This was overcome by using experience operators working with those who hadn't seen portal excavation before.

Don't forget QAQC. Many projects would benefit from greater levels of testing of the installed ground support items. This should not only cover individual elements such as grout and shotcrete tests, but verification that the support has been installed as per the design requirements.

You can never be too conservative in your portal design. This area is key to ensuring successful development and longevity. Seek a second opinion or external review.

\section{Conclusions}

Two portals were successfully designed and executed for the new mine. The process undertaken for this study indicated that there was a need to develop a framework for portal stability assessments as at the time there was not a lot of published literature on experiences and case studies of constructing underground excavations. Accordingly, the following guideline is proposed for portal investigations in old open pits.

1. Investigate historical data. Try and find as much information as possible on the open pit design parameters, historical test work, mapping, driller's plods, production rates etc. By trying to find as much of this information as possible you are not going into the project as blind as you otherwise would.

2. Pit stability assessment. Using the historical data, reconcile the current pit against the proposed design. At the very minimum you can use existing failures as a back-analysis for material properties, and if there are no failures then you can do a back-analysis to determine the actual minimum strength parameters of the material you are dealing with. If your budget permits, take some more samples for rock mass properties testing. If the pit has not been operational in a while then some sort of assessment of its current and future stability needs to be made to assess reentering this area. An assessment of the bench stability should also be undertaken to determine the suitability of the bench for cutting a portal. This will also help to determine the amount of support that is required in the bench face to keep it stabilised.

3. Field Investigation. In this phase you want to collect your own data. Mapping should be conducted as a minimum. Diamond drilling along the proposed decline alignment is considered a must in reducing the risk to the project. This is important for determining the stable excavation sizes and 
the amount of ground support required to keep the face stable, and alerting you to any unfavourably or unexpected ground conditions. Of key importance is to look for the presence of any large scale structural features that may be detrimental to the portal and bench stability. For this purpose the use of underground diamond drilling contractors is recommended, particularly if they already are on site. These types of drill rigs appear to be the most efficient for drilling shallow dipping holes. Collect and sample new core for rock properties testing.

4. Analysis. The data should be analysed bearing in mind that a portal required a combination of pit stability and underground stability techniques. For the open pit, consideration should be given to numerical analysis techniques to analyse rock mass stability. An analysis should also be done for the stability of structures for the face but also for the underground tunnel.

5. Design. When designing the ground support ensure that the design is realistic in terms of physically being able to be executed without exceeding the budget. Do not forget that this is a life of mine excavation and a high traffic area.

6. Construction. Communication is key. Ensure that all parties are clear with the direction that needs to be taken. Make sure that survey is engaged throughout the process. Take small firings initially to establish the portal. Instead of firing the full $4 \mathrm{~m}$ round, fire $2 \mathrm{~m}$ round to begin with. Where possible pre-install support or pre-reconstruct arches. This provides more immediate support and also helps to improve cycle times. Where portals are designed in weak rock masses then it may be necessary to modify blasting practices. Completion or sign-off sheets are necessary to make sure ground support is being installed as per the design.

7. Monitoring and supervision. A strict regime of monitoring is required combining visual (frequent inspections) and instrumentation. These will tell you how your excavation is performing and if it is having an effect on the stability of a slope, and if you need to make any changes.

\section{Acknowledgements}

The authors would like to thank Frans Basson and Mike Hildebrand of Newmont Asia Pacific for allowing the publishing of this paper and for technical guidance. We would also like to thank Stu Perazzo and Krissy Dudgeon for their help in creating figures and providing photographs.

\section{References}

Barton, N., Lien, R. and Lunde, J. (1974) Engineering Classification of Rock Masses for the Design of Tunnel Support, Rock Mechanics, Vol. 6, No. 4, pp. 183-236.

Cassidy, K.F., Champion, D.C., Krapež, B., Barley, M.E., Brown, S.J.A., Blewett, R.S., Groenewald, P.B. and Tyler, I.M. (2006) A revised geological framework for the Yilgarn Craton, Western Australia: Western Australia Geological Survey, Record 2006/8, 8 p.

Hutchinson, D.J. and Diederichs, M. (1996) Cablebolting in Underground Mines, BiTech Publishers, Richmond, 406 p.

Rogers, G.K. and Haycocks, C. (1989) Rock Classification for portal design, in Proceedings the 30th U.S. Symposium on Rock Mechanics (USRMS), 19-22 June 1989, Morgantown, USA.

Rogers, G.K. and Haycocks, C. (1988) Portal stability in Rock, in Proceedings Seventh International Conference on Ground Control in Mining, 3-5 August 1988, Morgantown, USA, pp. 76-83.

Singh, B., Jethwa, J.L. and Dube, A.K. (1995) A classification system for support pressure in tunnels and caverns, Journal of Rock Mechanics and Tunnelling Technology, Vol. 1(1), pp. 13-24.

Terzaghi, K. (1946) Introduction to tunnel geology, Rock Tunnelling With Steel Supports, R.V. Proctor and T.L. White (eds), Commercial Shearing and Stamping Co., Youngstown, p. 271. 